\title{
GPPS-BJ-2019-0047
}

\section{Ignition failure modes during ignition kernel propagation in swirl spray flames}

\author{
Xiaotong Mi, Chi Zhang, Xin Hui, Yuzhen Lin \\ National Key Laboratory of Science and \\ Technology on Aero-Engine Aero- \\ thermodynamics, Collaborative Innovation \\ Center of Advanced Aero-Engine, School of \\ Energy and Power Engineering, \\ Beihang University \\ Email: mixiaotong@buaa.edu.cn \\ Beijing, 100191, PR China
}

\author{
Hukam C. Mongia \\ CSTI Associates, LLC \\ Email: hmongia43@hotmail.com \\ Yardley, PA 19067, USA
}

\author{
Kyle Twarog, Chih-Jen Sung \\ Department of Mechanical \\ Engineering, \\ University of Connecticut \\ Email: kyle.twarog@uconn.edu, \\ chih-jen.sung@uconn.edu \\ Storrs, CT 06269, USA
}

\begin{abstract}
Technological advances for lowering the emissions of rich burn-quick mix-lean burn (RQL) combustors in response to increasingly stringent emissions regulations will be accompanied by more challenging operability issues, especially ignition along the flight envelope for both conventional and alternative aviation fuels. The aim of this paper is to research the ignition failure modes during ignition kernel propagation in swirl spray flames. These experiments were conducted on an optically accessible single fuel nozzle RQL model combustor featuring a fuel-air mixing device and combustor primary and dilution zones established by two rows of primary/dilution jets. The ignition tests were performed at both atmospheric and sub-atmospheric pressures, and the total pressure loss across the liner varied from $1 \%$ to $6 \%$. A highspeed camera was utilized to capture images of the kernel and flame propagation during the ignition process. The camera frame speed rate was $6750 \mathrm{~Hz}$ with $1 / 51000 \mathrm{~s}$ exposure time and the image resolution of $768 \times 768$ pixels covering $80 \times 80$ $\mathrm{mm}^{2}$ field view of the combustor considered critical for the investigation. In the successful ignition case, the initial ignition kernel generated near the igniter was transported and stabilized downstream of the swirler exit, followed by stable combustion covering the entire combustor. In the failed ignition cases, the ignition kernel underwent a series of
\end{abstract}

breakups following its formation. In these failure cases, parts of the sub-kernel were extinguished while the rest moved downstream towards the combustor exit, indicating that the kernel was not transported to the primary zone flame stabilizing portion of the combustor. Three ignition failure modes were determined from the high-speed images: ignition kernel "extinction", ignition kernel "breakup", and ignition kernel "downstream movement". While flameout in gas turbine combustors is mainly caused by aerodynamic quenching and/or fuel starvation, the alternation of ignition failure modes can be correlated with the fuel-air ratio and air mass flow rate.

\section{INTRODUCTION}

Ignition performance is an elementary requirement for a practical combustion device. The initiation and subsequent establishment of combustion are vital for any combustion system, especially for an aero-engine combustor (Mastorakos, 2017). In response to increasingly stringent emissions regulations, technological advances for lowering the emissions of rich-burn quick-mix lean-burn (RQL) combustors will be accompanied by operability challenges including reliable ignition throughout the flight envelope for both conventional and alternative aviation fuels. The key design features for these ultra-low emission combustors are fuel-air mixing mechanisms and combustor primary/dilution 
zones (PZ-DZ) established by primary/dilution jets (Mongia, 2011a, 2011b).

The ignition process of a typical gas turbine combustor has three distinct phases: kernel generation, flame growth, and flame establishment. As ignition failure may occur in any phase, Mastorakos (2017) has defined three different ignition failure modes. An ignition spark with energy lower than the minimum ignition energy or a spark whose energy has been lost to highly turbulent flow can lead to ignition failure in the kernel generation phase. As modern igniters are designed with these points in mind, these failure modes are uncommon in modern combustors. More relevant to current practice are the modes of ignition failure in the flame growth and flame establishment phases, such as flame kernel extinction caused by the fluctuation of local equivalence ratio and kernel advection downstream caused by the airflow pattern.

The current diagnostic techniques used for studying ignition behaviour in gas turbine combustors include the use of a high-speed camera to record the ignition sequence and kernel movement path, laser Doppler anemometry to determine the gas phase velocity, particle image velocimetry or phase Doppler analyser to determine the liquid phase velocity, and planar Mie scattering or tomography scattering to determine the fuel spray distribution. Read et al. (2010) studied the high altitude relight behaviour of a lean direct injection gas turbine combustor using a high-speed camera and proposed four ignition failure modes within the flame growth and establishment phases: a) rapid disintegration, b) flame exit, c) flame split, and d) lack of flame stabilization at the injector. Mosbach et al. (2010) also researched the high altitude relight process of a lean combustor using a high-speed camera and found that stable ignition and flame establishment were closely related to the flow field, fuel spray distribution, and local equivalence ratio distribution. Flame kernels that were convected into the central recirculation zone of the combustor typically led to flame stabilization, whereas those flame kernels convected towards the combustor exit typically extinguished. The ignition process research conducted by (Rosa et al., 2011; Lecourt et al., 2011; Linassier et al., 2011; Linassier et al., 2012) investigated the effect of both the fuel and air flow fields on the ignition process using a high-speed camera. Ignition failure was noted to be caused by kernel extinction and advection downstream. Wang et al. (2016) studied the influence of swirler vane angle on the ignition performance of the TeLESS-II combustor by experimentally measuring the pilot stage fuel spray distribution and ignition kernel movement path, combined with numerical analysis of the flow field and fuel distribution, and concluded that the local fuel-air ratio had a greater impact on ignition than the flow field. While the abovementioned research reached a consistent conclusion that the flow field and fuel distribution patterns have a direct influence on ignition performance, the flow field and fuel distribution characteristics of different ignition failure modes as well as the relationship between them have not been systematically studied.

In order to conduct a fundamental investigation of ignition/mixer and PZ-DZ emissions/ignition tradeoffs it is important to utilize modern mixers. In this case, we adopted a counter-turning-swirlers (CTS) design, along with a compact PZ-DZ design utilizing modern liner cooling technology burning the Chinese aviation kerosene RP-3. As ignition in a gas turbine combustor is closely related to its temporal and spatial flow field and fuel distribution characteristics, it is necessary to investigate the correlation between ignition kernel path and temporal and spatial flow-fuel interactions in the region of the kernel path. As the first stage of this series of research, this paper focuses on the determination of the ignition failure modes, the ignition kernel path, and the relationship between ignition failure modes and flow field/fuel distribution characteristics. Specifically, the objectives of the present work are (1) to determine the ignition failure modes and kernel path based on high-speed imaging of ignition events and (2) to investigate the relationship between ignition failure modes and the time-averaged flow field and fuel distribution utilizing computational fluid dynamics (CFD) simulations.

\section{METHODOLOGY}

\section{Single-element model combustor}

A single-element RQL model combustor was used in the present work, as shown schematically in Fig. 1. The model combustor was based on an engine layout with a significant difference in the discharge radii of the compression system and the inlet radii of the high-pressure turbine system, resulting in a canted annular combustion system with attendant outer prediffuser layout. This single fuel nozzle model combustor had a length of $16 \mathrm{~cm}$ and a volume of $1297.1 \mathrm{~cm}^{3}$. A dual axial counter-swirler assembly was used in these tests. This assembly comprised of a clockwise rotating inner swirler and a counter-clockwise rotating outer swirler. It should be noted that this CTS mixer configuration is distinctly different from those used by GE Aviation (Mongia, 2011a), Rolls Royce (Willis and Moran, 2000), and Pratt \& Whitney (Mckinney et al., 2007). Following Huang and Yang (2009), the swirl numbers of the inner and outer swirlers were calculated by $\mathrm{S}=\frac{2}{3}\left[\frac{1-\left(R_{o} / R_{i}\right)^{3}}{1-\left(R_{o} / R_{i}\right)^{2}}\right] \tan \alpha$, where $R_{o}$ and $R_{i}$ are the outer and inner radii of the swirler vane, respectively, and $\alpha$ is the swirler vane angle. The resulting swirl numbers of the inner and outer swirlers were 0.972 and 1.095 , respectively. A transparent quartz window on the side wall of the rectangular test combustor provided optical access for observation and diagnostics. The igniter was located $35 \mathrm{~mm}$ downstream of pilot swirl cup exit, and the axial position of the igniter was located slightly upstream $(\sim 0.6 \mathrm{~mm})$ of the primary hole. The fuel nozzle, with the pilot flow number of $12.52 \mathrm{~kg} / \mathrm{h}$. $\mathrm{MPa}^{0.5}$ and the dual-orifice flow number of $56.92 \mathrm{~kg} / \mathrm{h}$. $\mathrm{MPa}^{0.5}$, injected fuel into the CTS mixer. However, for this study only the pilot fuel passage was utilized. 


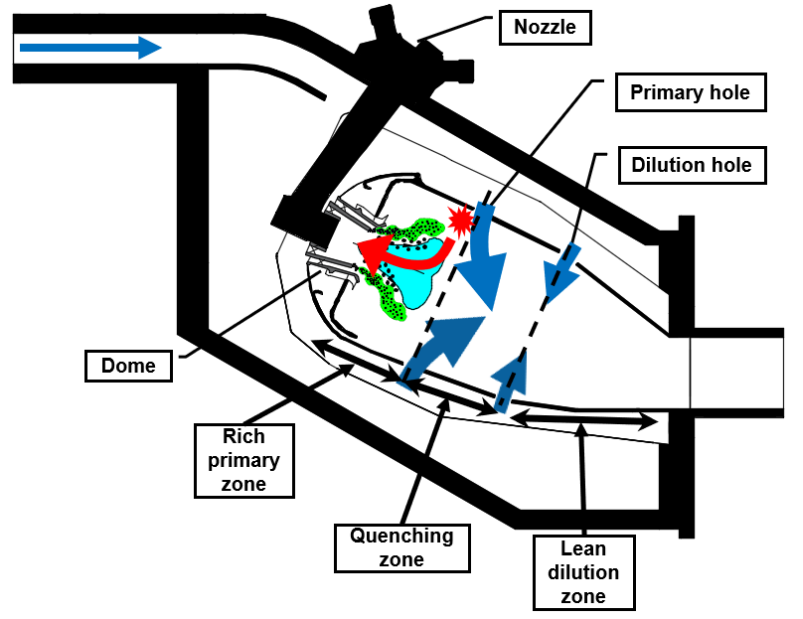

Fig. 1 Schematic of the current RQL model combustor

\section{Experiment system}

The ignition test system was composed of an air supply system, fuel supply system, ignition control system, measurement system, and high-speed imaging system, as shown in Fig. 2. In the atmospheric ignition test configuration (Fig. 2a), air was supplied to the combustor via a highpowered fan, and the total combustor air mass flow rate, $\mathrm{Wa}_{31}$, was controlled by varying the fan speed and the state of restricting valves downstream of the fan. In the high altitude ignition test configuration (Fig. 2b), two vacuum pumps in the exhaust path were utilized to evacuate the test section so as to provide a low pressure environment, and the total combustor air mass flow rate was controlled by utilizing a set of adjustable valves as flow restrictions located upstream of the test section.

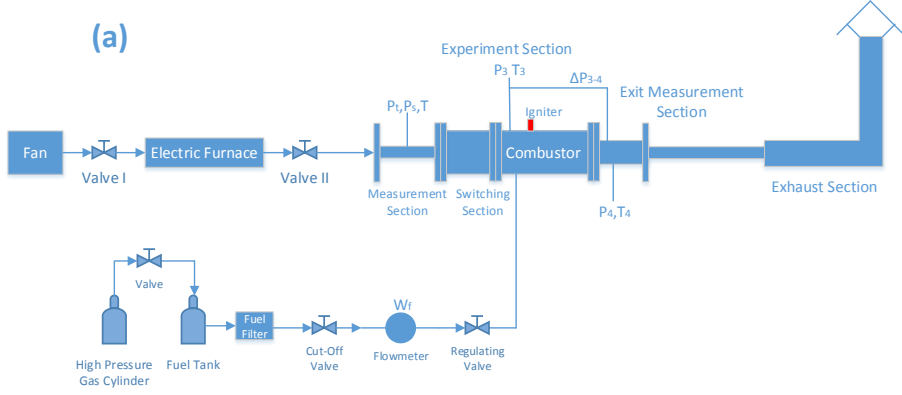

(b)

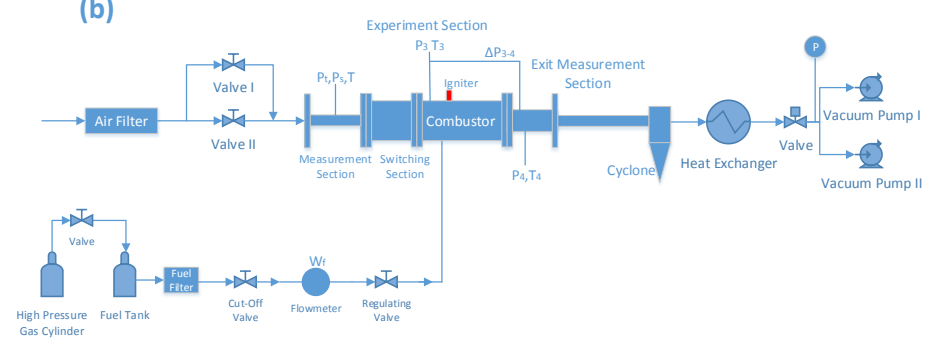

Fig. 2 Schematic of (a) atmospheric ignition and (b) high altitude ignition test systems

The fuel used in these tests was Chinese aviation kerosene RP-3 with no additives. The fuel composition was determined utilizing the standard gas chromatography-mass spectrometer method and is summarized in Table 1. The tested RP-3 fuel had a density of $0.795 \mathrm{~g} / \mathrm{cm}^{3}$, a kinematic viscosity of 1.786 $\mathrm{mm}^{2} / \mathrm{s}$ at $20{ }^{\circ} \mathrm{C}$, an $\mathrm{H} / \mathrm{C}$ ratio of 1.956 , and an average molecular weight of $173.1 \mathrm{~g} / \mathrm{mol}$; its chemical formula can be represented by $\mathrm{C}_{12.38} \mathrm{H}_{24.21}$ with a stoichiometric fuel-air mass ratio of 0.068 . Fuel was supplied to the experiment via a nitrogen charged hydraulic accumulator. For ignition testing, a surface-discharge igniter was used in conjunction with a high-energy ignition unit, with the igniter tip being flush with the liner surface.

Table 1 Composition of tested RP-3

\begin{tabular}{cc}
\hline Composition & Mass percentage \\
\hline Alkanes & $46.0 \%$ \\
Cycloalkanes & $43.4 \%$ \\
Aromatics & $10.6 \%$ \\
\hline
\end{tabular}

Diagnostics utilized in the ignition tests included total pressure piezometers, a differential pressure gauge, a fuel nozzle pressure gauge, a fuel Coriolis force flowmeter, and Ktype thermocouples. The mass flow rate of the total inlet air stream was calculated utilizing the air pressure drop of the measurement section with a pressure measurement precision of $1.0 \%$. The relative error of the calculated air flow rate was approximately $2.1 \%$. The fuel mass flow rate was measured using a Coriolis force flowmeter with a full-scale range of 0 $20 \mathrm{~kg} / \mathrm{h}$ and an accuracy of $1.5 \%$ of the full scale. The K-type thermocouple possessed a measurement precision of $0.5 \%$. The total pressure of inlet air $\left(\mathrm{P}_{3}\right)$ of the liner was measured in the pipe upstream of the test section, and the outlet total pressure $\left(\mathrm{P}_{4}\right)$ was measured adjacent to the exit of the liner. The liner case also had a transparent quartz window on the side which provided optical access for observations of the flame kernel.

A high-speed camera (Photron FASTCAM SA4) was used in these experiments, with the images captured in the wavelength range of 400-1000 $\mathrm{nm}$. The camera lens was a Nikon AF-S Micro NIKKOR $60 \mathrm{~mm} \mathrm{1:2.8} \mathrm{G.} \mathrm{For} \mathrm{these} \mathrm{tests}$ the aperture utilized was F2.8 and the focusing distance was $470 \mathrm{~mm}$. The camera frame rate was $6750 \mathrm{~Hz}$, the exposure duration was $1 / 51000 \mathrm{~s}$, and the image resolution was $768 \times 768$ pixels corresponding to a field of view of $80 \times 80$ $\mathrm{mm}^{2}$.

The ignition tests were performed at both atmospheric pressure and low pressure so as to simulate high altitude conditions. The overall pressure loss across the liner, $\Delta \mathrm{P}_{3-4} / \mathrm{P}_{3}$, varied from $1 \%$ to $6 \%$. The ignition tests began with a FAR of 0.05 and the minimum lean light off FAR was then determined by reducing the fuel flow rate gradually until ignition could no longer be achieved at a given liner air pressure drop condition. By changing the liner air pressure drop and repeating the aforementioned process, the ignition boundary was determined. The igniter was deactivated when the outlet temperature $\left(\mathrm{T}_{4}\right)$ exhibited a sudden surge suggesting that ignition had occurred, and the continuous activation period of the igniter did not exceed 15 seconds, as shown in Fig. 3.

The lean blowout (LBO) tests were conducted utilizing the atmospheric ignition experimental system as shown in Fig. 2a. LBO data were obtained by gradually reducing the fuel flow rate and recording the FAR at the time of extinction. A sudden drop in $\mathrm{T}_{4}$ was utilized to determine flameout, as shown in Fig. 3. By changing the liner pressure drop and 
repeating the aforementioned process, the LBO boundary was obtained.
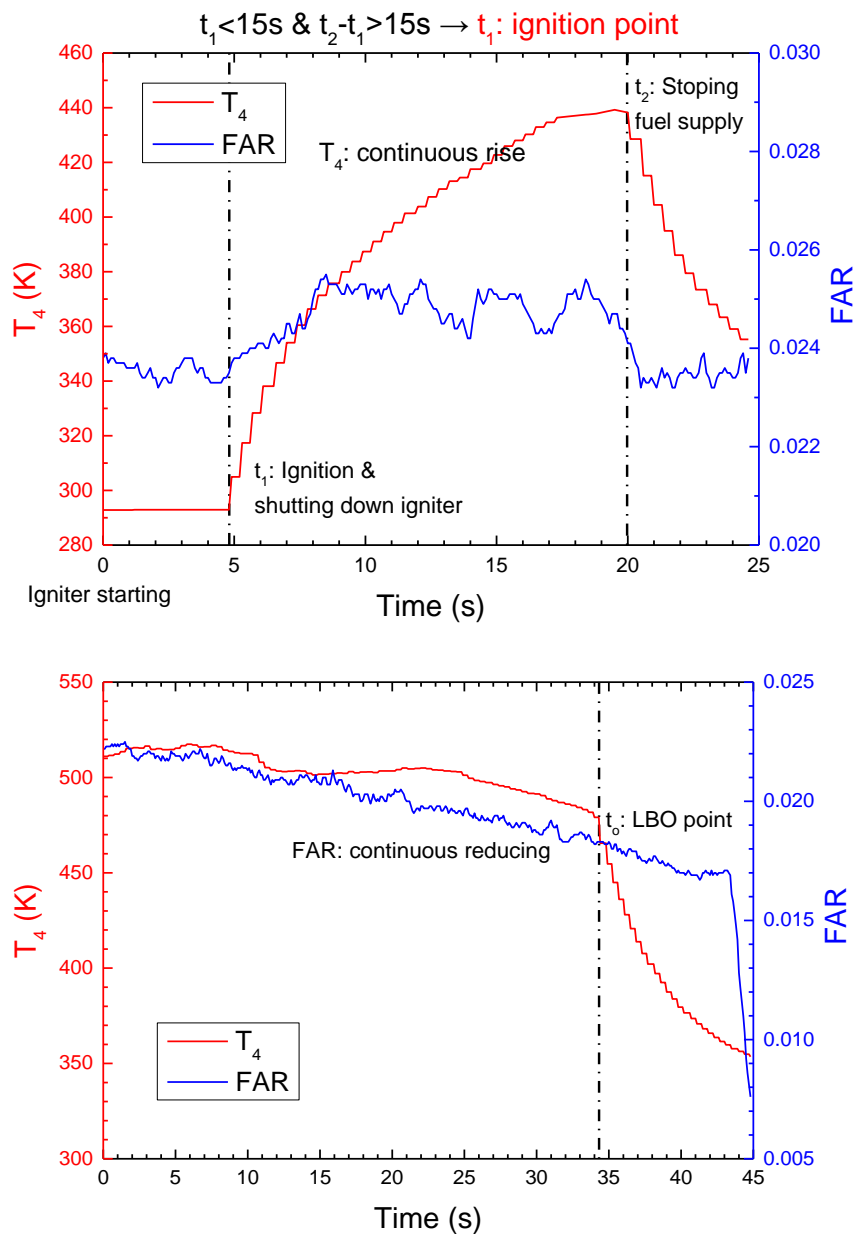

Fig. 3 Ignition and LBO criteria

\section{Numerical simulation}

A commercial CFD package, Ansys Fluent, was utilized for simulation of the current combustor. The mass-flow-inlet and pressure outlet boundary conditions were utilized. The realizable k- $\varepsilon$ model with enhanced wall treatment was used as the turbulence model (Mongia, 2008). Fluent's species transport model was also enabled, and the Discrete Phase Model (DPM) was utilized to simulate the fuel injector utilizing the pressure swirl atomizer and evaporating-droplet sub-models, with the kerosene droplet being represented chemically by $\mathrm{C}_{12} \mathrm{H}_{23}$ that is available in the Fluent database. The half spray cone angle was set as $45^{\circ}$ as determined from experimental measurements of the resulting spray. A wave breakup model was utilized and the discrete random walk model was chosen for stochastic tracking of DPM parcels. The fuel-initiated vaporization temperature was set as $273 \mathrm{~K}$. A reflection boundary condition was chosen for the venturi surface, with a normal reflection coefficient of zero and a tangent reflection coefficient of 0.2 . The reliability of this numerical method for predicting flow field and fuel distribution has been demonstrated in (Wang et al., 2016; Mi et al., 2017).

\section{RESULTS AND DISCUSSION}

\section{Ignition and LBO limits}

As the fuel-to-air mass ratio is defined as $F A R=\frac{\dot{m}_{f}}{W a_{31}}$, the measurement error of FAR is defined as

$$
e_{F A R}=\sqrt{\left(\frac{\partial F A R}{\partial \dot{m}_{f}}\right)^{2} e_{\dot{m}_{f}}{ }^{2}+\left(\frac{\partial F A R}{\partial W_{a}}\right)^{2} e_{W a_{31}}{ }^{2}}
$$

in which $e_{Q}$ is the measurement error of quantity Q, and $e_{\dot{m}_{f}}$ and $e_{W a_{31}}$ are $1.5 \%$ and $2.1 \%$ of the full scale, respectively, as stated in the "Experiment system" section.

Figure 4 shows that both the ignition boundary and LBO boundary at atmospheric pressure decrease with respect to an increase in $\Delta \mathrm{P}_{3-4} / \mathrm{P}_{3}$. At low pressure drop conditions, $\mathrm{Wa}_{31}$ was relatively low, forcing the fuel flow rate to also be relatively low so as to maintain a given FAR value. Accordingly, the atomization performance of the pilot injector was poor as a result of low aerodynamic force and low fuel pressure drop. As the pressure drop increased, the increase of $\mathrm{Wa}_{31}$ led to an improvement of atomization quality and overall fuel dispersion, allowing for superior formation and propagation behaviour of the initial ignition kernel. The LBO boundary was found to be slightly lower than the ignition boundary, with the difference between the two boundary curves being roughly constant throughout the tested conditions.

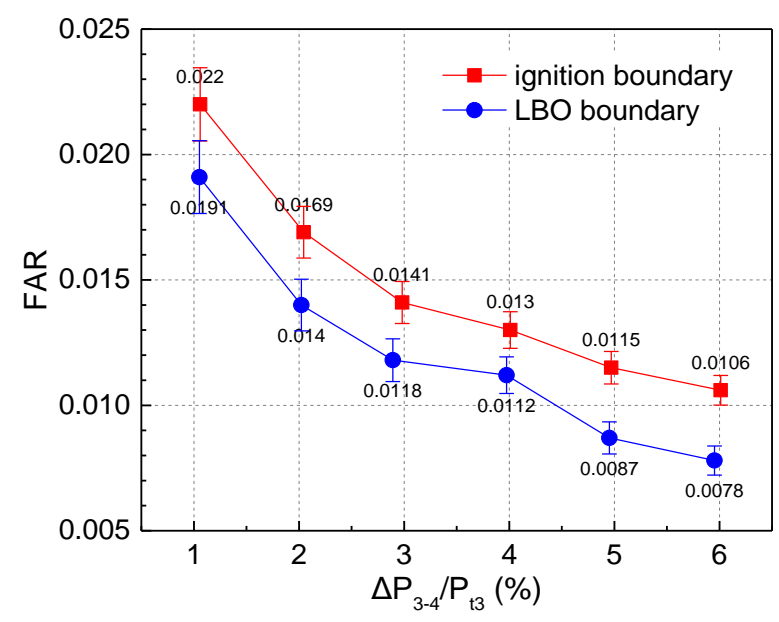

Fig. 4. Ignition and LBO performance of singleelement model combustor at atmospheric pressure

As to the high-altitude ignition results, Fig. 5 compares the ignition boundaries for various $\mathrm{P}_{3}$. The low pressure ignition boundaries all show similar downward trends that of the atmospheric ignition cases. As $\mathrm{P}_{3}$ increased from $35 \mathrm{kPa}$ to atmospheric pressure, the ignition boundary decreased dramatically, though this difference itself decreased with respect to increased pressure such that the difference between the $80 \mathrm{kPa}$ and atmospheric pressure cases was quite small. It should be noted that a successful ignition event could not be detected at the $4 \%$ and $5 \%$ pressure drop conditions when $\mathrm{P}_{3}=35 \mathrm{kPa}$, likely due to the unsatisfactory atomization performance of this injector under the conditions tested. In 
addition, a defined velocity nondimensional quantity was used to correlate with the ignition boundary data, as shown in Fig. 5. Here, $\mathrm{Vr}$ is the liner reference velocity, i.e. the mean air velocity through the primary holes, which was calculated under the assumption that the area of flow-path could be determined from rectangular transverse dimensions of the holes as measured in a three-dimensional modelling software, $\theta$ is the nondimensional temperature scaled by $288 \mathrm{~K}$, and $\delta$ is the normalized pressure scaled by $1 \mathrm{~atm}$. It can be seen from Fig. 5 that a fitted logarithmic curve approximates the various datasets, suggesting a logarithmic relationship between flow and fuel influence on ignition characteristics.
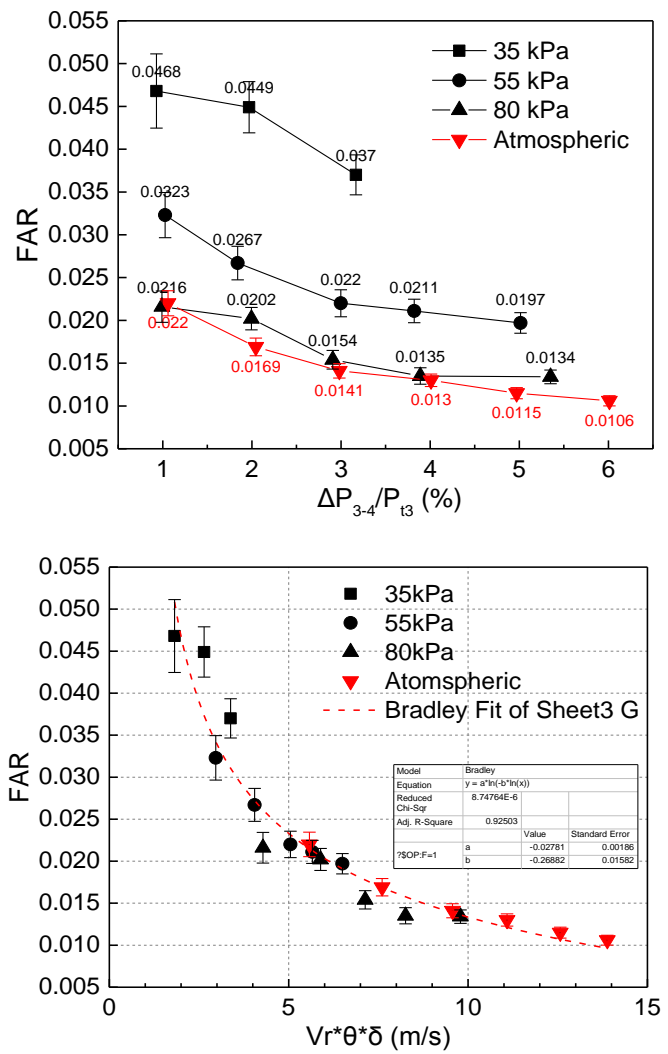

Fig. 5. Ignition boundary at atmospheric, 80 kPa, 55 $\mathrm{kPa}$, and $35 \mathrm{kPa}$ pressures

\section{Ignition sequence}

The recordings captured by the high-speed camera were analyzed so as to gain insight into the ignition process. The successful ignition processes all depicted an identical sequence, as shown in Fig. 6 where the case of $\Delta \mathrm{P}_{3-4} / \mathrm{P}_{3}=3 \%$ and $\mathrm{FAR}=0.016$ was taken as an example.

The igniter starting time was defined as $\mathrm{T}=0 \mathrm{~ms}$. In this process, a flame kernel was initially generated in the vicinity of the igniter, then moved along the vertical axis into the central recirculation zone $(\sim \mathrm{T}=1.2 \mathrm{~ms})$. After that, the flame kernel propagated upstream and the flame area enlarged $(\sim \mathrm{T}=4 \mathrm{~ms})$. Once propagation had completed, a burner-scale stable flame was established $(\sim \mathrm{T}=8 \mathrm{~ms})$. There was also a period of $\sim 1-7 \mathrm{~ms}$ during which the flame kernel dimmed and no light could be detected by the camera, a phenomenon which occurred frequently in the higher FAR cases. A possible explanation for this could be that more flame kernel energy was to be absorbed by the fuel evaporation process at these
FAR values, thereby dimming the kernel. Despite not being visible, the reaction was still in progress and the presence of fuel vapor and vital chemical species facilitated subsequent flame kernel propagation.
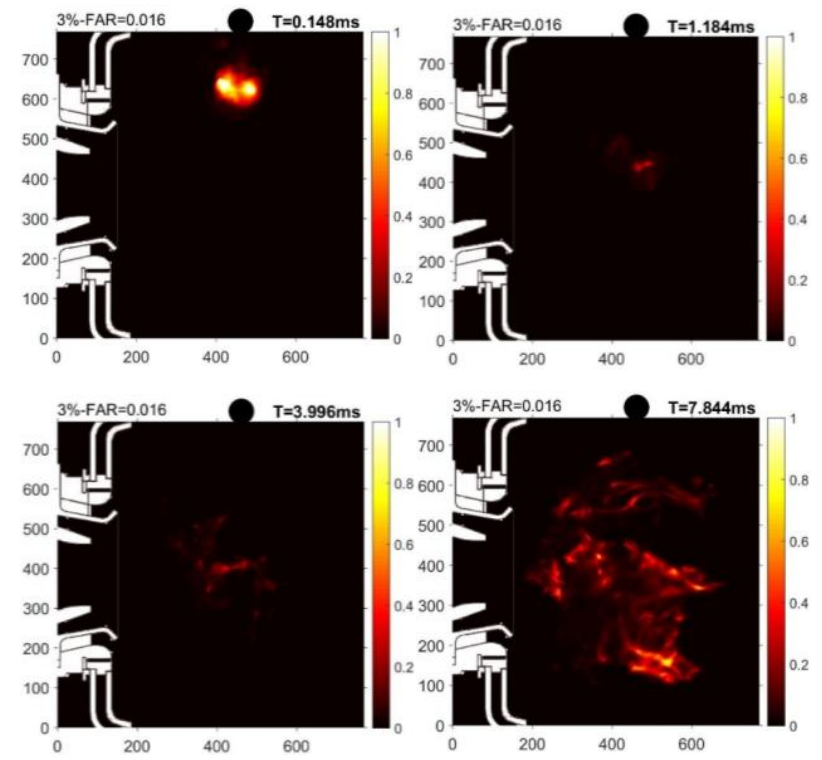

Fig. 6 Successful ignition sequence for $\Delta P_{3-4} / P_{3}=3 \%$ and $F A R=0.016$

\section{Ignition failure modes}

Three ignition failure modes were distinguished from the high-speed records of the ignition process, i.e. (a) extinction, (b) breakup, and (c) downstream movement, as shown in Fig. 7. For the first mode, "extinction" in Fig. 7a, it is clear that the flame kernel was quenched in the process of moving into the central recirculation zone. In regards to the second mode, "breakup", two ignition kernel breakups were observed at $1.036 \mathrm{~ms}$ and $2.368 \mathrm{~ms}$. The sub-kernels were either extinguished or moved downstream towards the combustor exit, and the remaining kernel portion within the central recirculation zone was too weak to sustain flame propagation, as shown in Fig. 7b. The third mode, "downstream movement" in Fig. 7c, was depicted as a downstream movement of the kernel to a region devoid of fuel, indicating that no portion of the kernel was transported downstream of swirler.

In order to quantitatively demonstrate the difference between successful ignition and the different ignition failure modes, the flame kernel path and the maximum light intensity were compared in Fig. 8 and Fig. 9, respectively. Here, the kernel position was determined to be the two-dimensional geometric center of area with the maximum light intensity. The three ignition failure modes can be identified through the kernel paths shown in Fig. 8. The "extinction" mode was marked by a distinct upstream movement and blowout inside the central recirculation zone. Similarly, the "downstream movement" mode was characterized by a downstream movement of the ignition kernel. On the other hand, the "breakup" mode did not possess a singular distinct kernel movement. From the perspective of normalized maximum light intensity, the ignition kernel quenching of the "extinction" mode and the "downstream movement" mode occured within $2 \mathrm{~ms}$, while the "breakup" mode lasted for a longer time span of roughly $4 \mathrm{~ms}$, as shown in Fig. 9a. A 
possible reason for this could be that the ignition kernel actually experienced multiple breakup processes during this time before completely extinguishing.
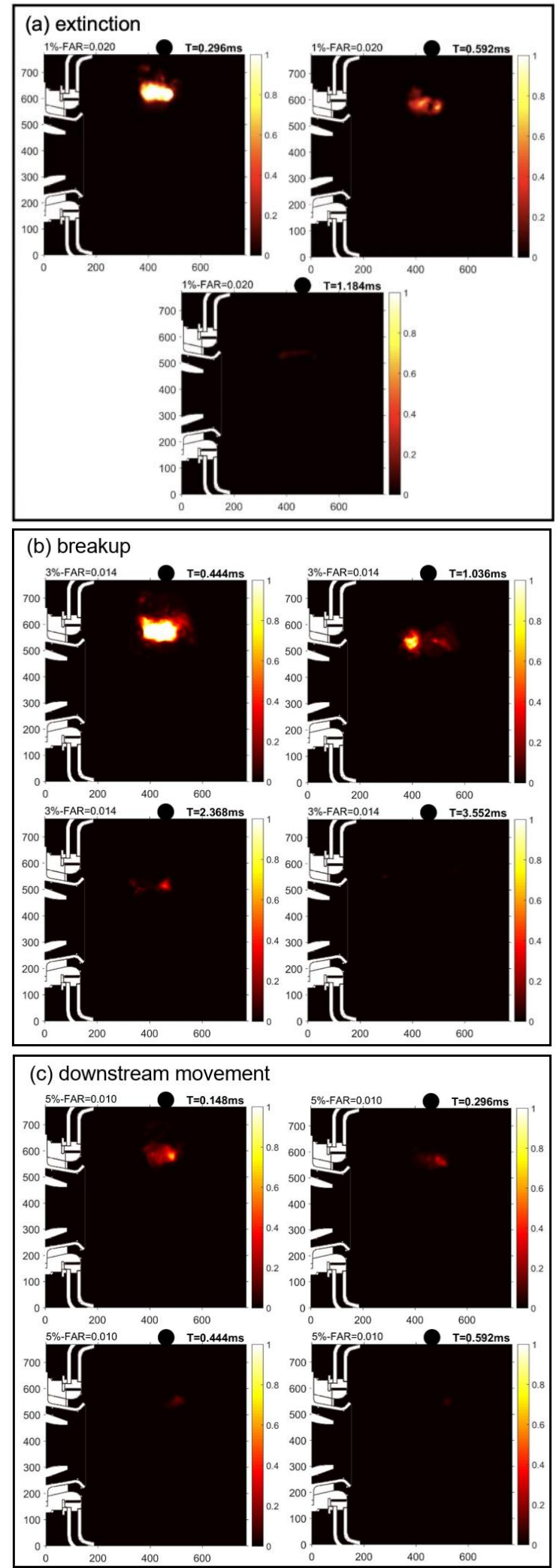

Fig. 7 Ignition failure modes: (a) extinction at $\Delta P_{3-}$ ${ }_{4} / P_{3}=1 \%$ and $F A R=0.020$, (b) breakup at

$\Delta P_{3-4} / P_{3}=3 \%$ and $F A R=0.014$, (c) downstream movement at $\Delta P_{3-4} / P_{3}$ and $F A R=0.010$

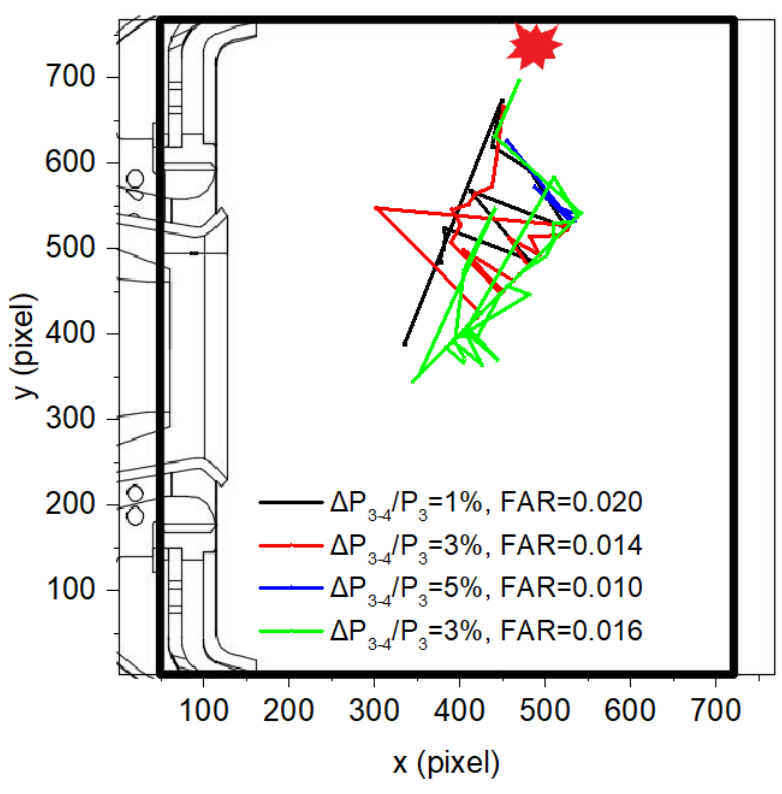

Fig. 8 Kernel path lines superimposed on the combustor schematic, with the igniter being represented by the red spark and the limits of the quartz window being represented by the black rectangle

Figures 9b-9d compare the normalized maximum light intensity data of the same $\Delta \mathrm{P}_{3-4} / \mathrm{P}_{3}$ condtions, $1 \%, 3 \%$, and $5 \%$, respectively. In some successful ignition cases, there were periods of time in which the normalized maximum light intensity dropped to values close to zero. For the condition of $\Delta \mathrm{P}_{3-4} / \mathrm{P}_{3}=1 \%$ this period lasted roughly $2.5 \mathrm{~ms}$ (cf. Fig. $9 \mathrm{~b}$ ), while at $\Delta \mathrm{P}_{3-4} / \mathrm{P}_{3}=5 \%$ this period lasted roughly $7 \mathrm{~ms}$ (cf. Fig. 9d). 

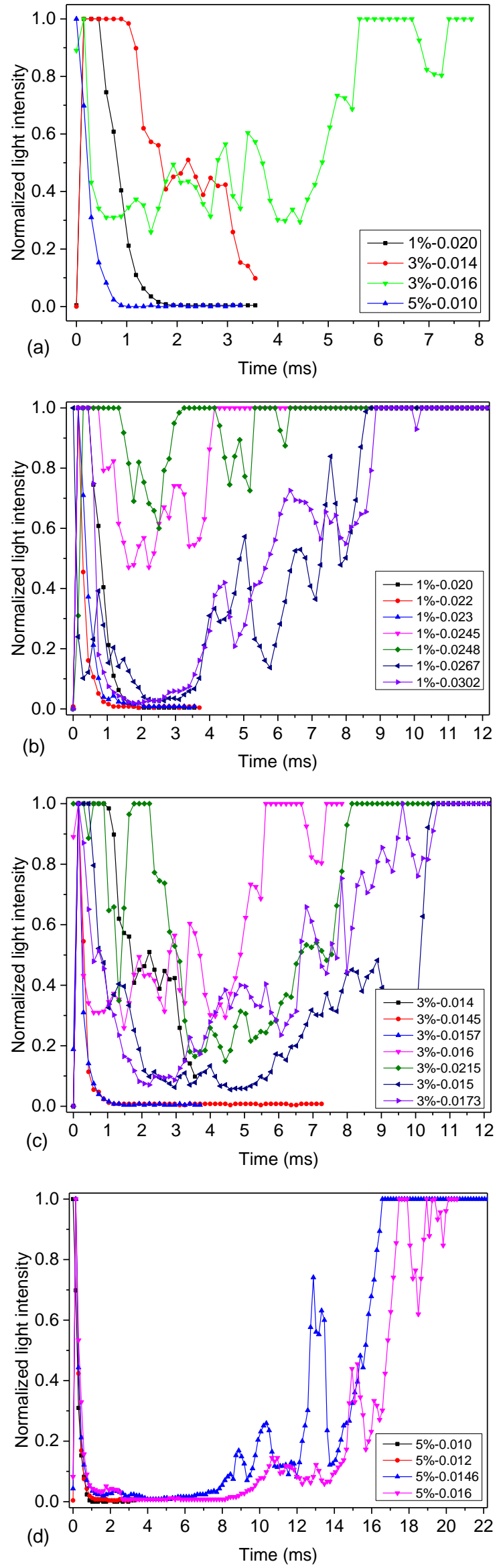

Fig. 9 Normalized kernel light intensity
Relationship between ignition failure modes and time-averaged flow field and fuel distribution

In order to explain the causes of the different ignition failure modes, CFD simulations of the flow field and fuel distribution were conducted at specific conditions representative of the three ignition failure modes, as listed in Table 2.

Table 2 CFD simulation conditions

\begin{tabular}{|c|c|c|c|c|}
\hline Case & $\Delta \mathrm{P}_{3-4} / \mathrm{P}_{3}$ & $\begin{array}{l}\mathrm{Wa}_{31} \\
(\mathrm{~g} / \mathrm{s})\end{array}$ & FAR & $\begin{array}{l}\text { Corresponding } \\
\text { mode }\end{array}$ \\
\hline $\bar{a}$ & $1 \%$ & 57 & 0.020 & extinction \\
\hline b & $3 \%$ & 102 & 0.014 & breakup \\
\hline $\mathrm{c}$ & $3 \%$ & 102 & 0.016 & success \\
\hline d & $5 \%$ & 137 & 0.010 & $\begin{array}{c}\text { downstream } \\
\text { movement }\end{array}$ \\
\hline
\end{tabular}

As shown in Fig. 10 and Fig. 11, the structure of the nonreacting flow field changed very little from case to case. A large-scale low velocity region, i.e. the inner recirculation zone, was formed downstream of the swirler exit. High speed jet flows could clearly be seen at the primary holes and dilution holes of the liner. The main difference in the flow field between cases was the absolute velocity magnitude, particularly for those of the jets emanating from the primary and dilution holes on liner. For example, the primary hole jet speed was $47.6 \mathrm{~m} / \mathrm{s}$ for the $\Delta \mathrm{P}_{3-4} / \mathrm{P}_{3}=1 \%$ case and $114.4 \mathrm{~m} / \mathrm{s}$ for the $\Delta \mathrm{P}_{3-4} / \mathrm{P}_{3}=5 \%$ case. The representative jet speed was probed at a point $5 \mathrm{~mm}$ from the entry plane of the jet along the central axis of the jet. This is represented in Fig. 10 by a gray square. It should be noted that the canted orientation of this combustor as well as the radial location of the air inlet resulted in an asymmetrical pressure profile with respect to the central axis of the combustor, as shown in Fig. 12, leading to slight asymmetries in the velocity contours within and close to the swirler. 


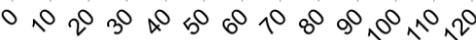

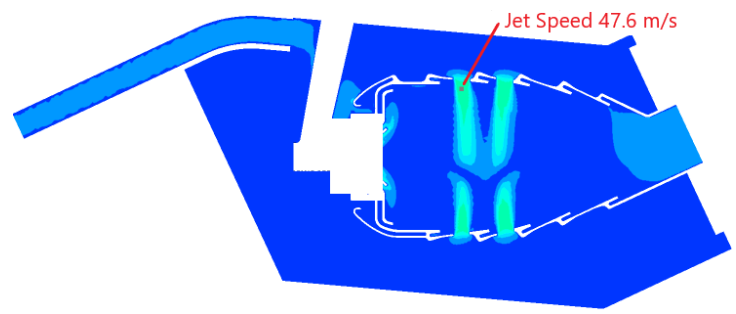

(a) $1 \%-F A R=0.020$

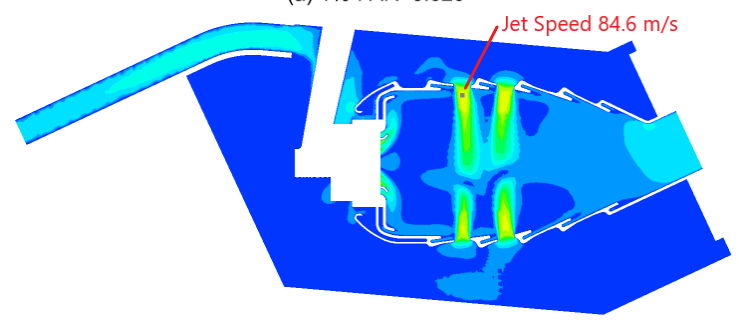

(b) $3 \%-F A R=0.014$

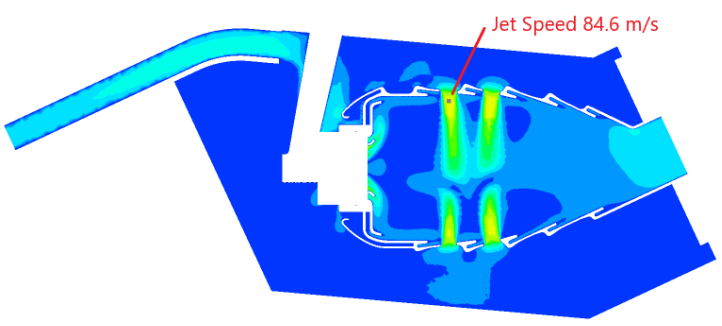

(c) $3 \%-F A R=0.016$

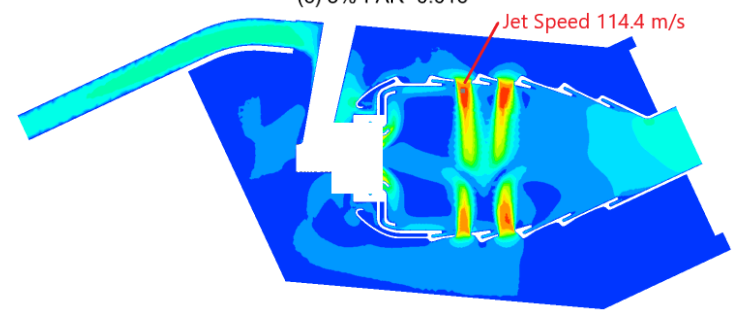

(d) $5 \%-F A R=0.010$

Fig. 10 CFD non-reacting flow field features at the central plane corresponding to Table 2:

(a) $\Delta \mathrm{P}_{3-4} / \mathrm{P}_{3}=1 \%$ and $F A R=0.020$, (b) $\Delta \mathrm{P}_{3-4} / \mathrm{P}_{3}=3 \%$ and FAR $=0.014$, (c) $\Delta P_{3-4} / P_{3}=3 \%$ and $F A R=0.016$, (d) $\Delta P_{3-4} / P_{3}=5 \%$ and $F A R=0.010$

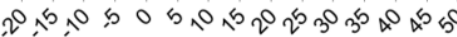

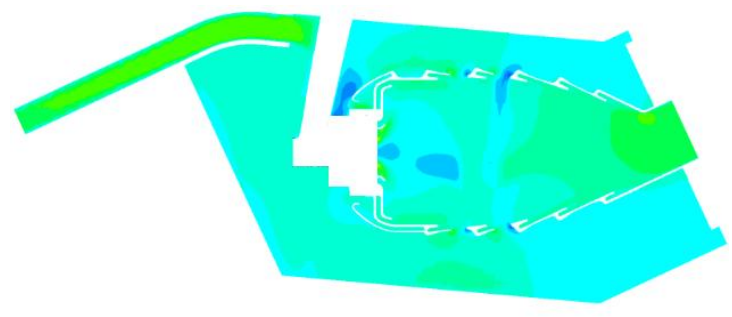

(a) $1 \%-F A R=0.020$

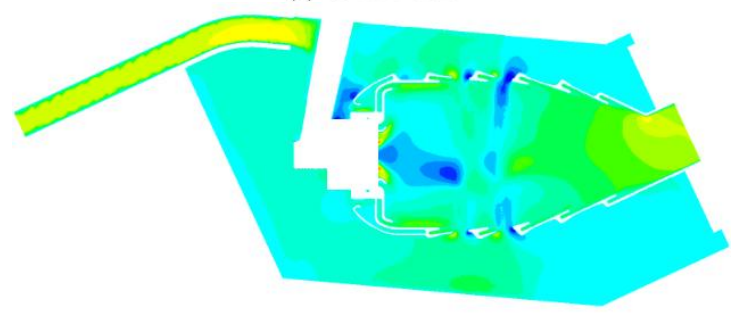

(b) $3 \%-F A R=0.014$

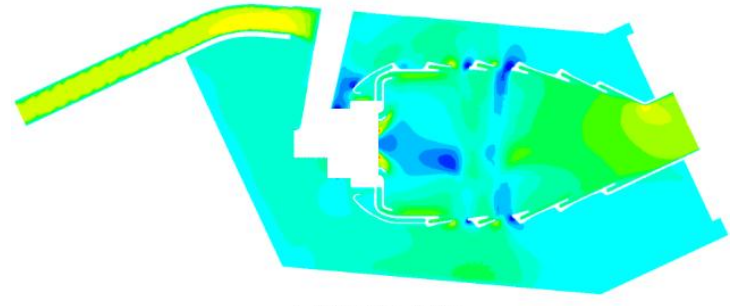

(c) $3 \%-F A R=0.016$

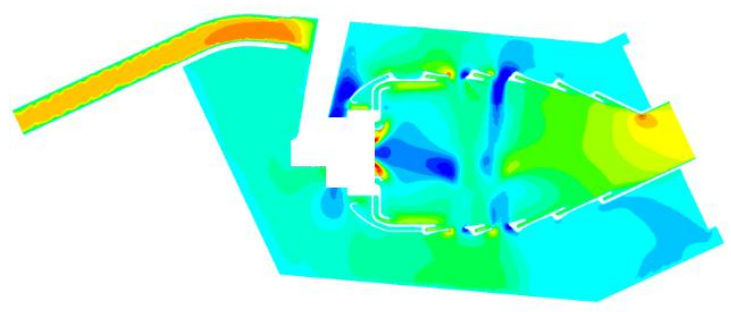

(d) $5 \%$-FAR $=0.010$

Fig. 11 Axial velocity contours at the central plane corresponding to Table 2: (a) $\Delta \mathrm{P}_{3-4} / \mathrm{P}_{3}=1 \%$ and

$F A R=0.020$, (b) $\Delta P_{3-4} / P_{3}=3 \%$ and $F A R=0.014$, (c) $\Delta P_{3-4} / P_{3}=3 \%$ and $F A R=0.016$, (d) $\Delta P_{3-4} / P_{3}=5 \%$ and FAR $=0.010$

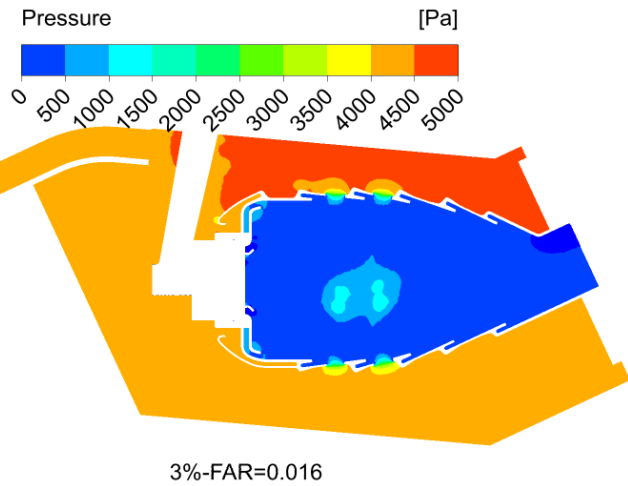

Fig. 12 Gauge total pressure profile for the $\Delta P_{3-4} / P_{3}=3 \%$ and $F A R=0.016$ case. 

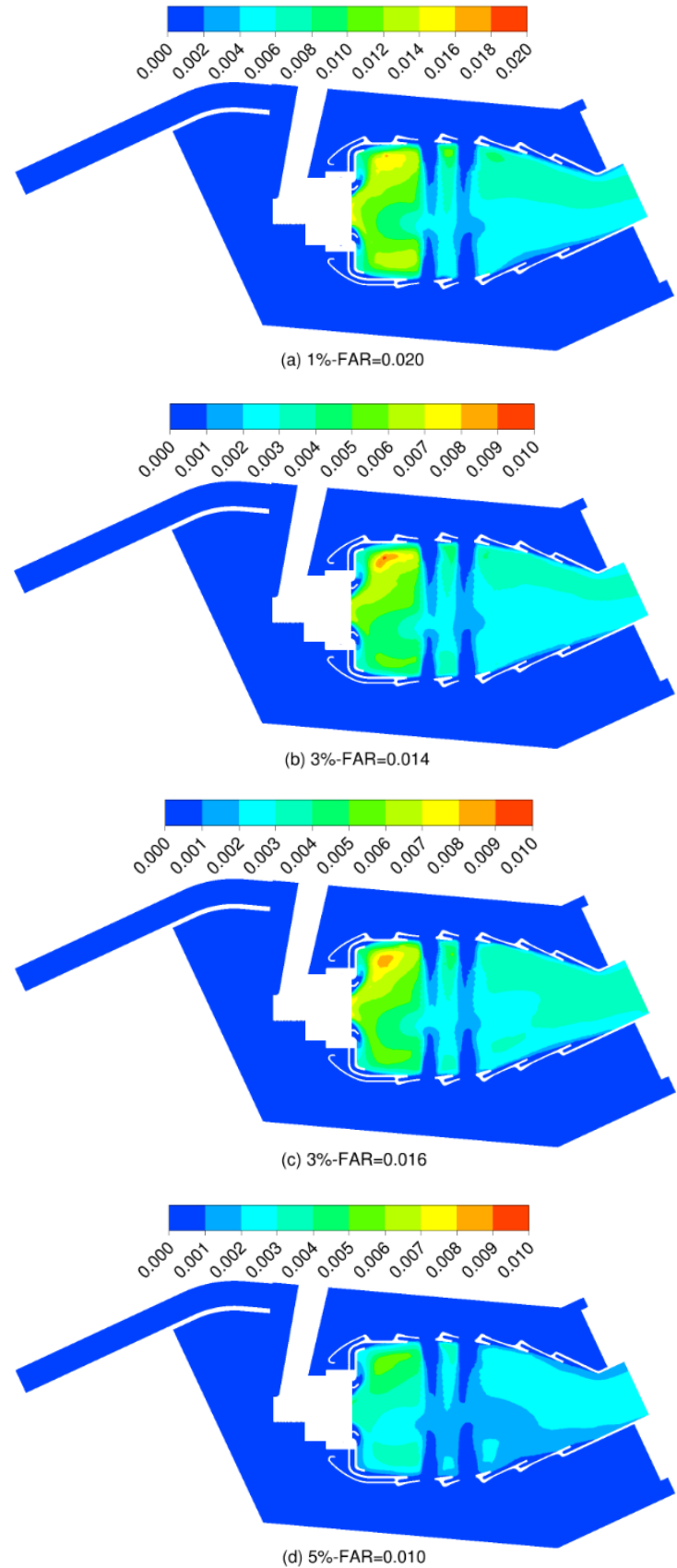

Fig. 13 CFD non-reacting fuel distribution (FAR derived from gaseous kerosene mass fraction) at the central plane corresponding to Table 2:

(a) $\Delta \mathrm{P}_{3-4} / \mathrm{P}_{3}=1 \%$ and FAR $=0.020$, (b) $\Delta \mathrm{P}_{3-4} / \mathrm{P}_{3}=3 \%$ and $F A R=0.014$, (c) $\Delta P_{3-4} / P_{3}=3 \%$ and $F A R=0.016$, (d) $\Delta P_{3-4} / P_{3}=5 \%$ and FAR $=0.010$

Figure 13 illustrates the non-reacting fuel distribution in the form of FAR corresponding to the gaseous kerosene mass fraction. As these simulations were non-reactive, the derived FAR is not an absolute index but can act as a qualitative description of fuel distribution. As was stated previously, the axial position of igniter was located slightly upstream ( 0.6 $\mathrm{mm}$ ) of the primary hole. With that in mind, it can clearly be seen in Fig. 13 that the relatively high FAR zone took the form of a hollow cone shape and a local high FAR area appeared close to the spark region.
Although the FAR of Case (a) was much higher than those of the other cases, it should be noted that the overall air mass flow rate was lower than those of the other cases due to the lower air pressure drop value of Case (a). The relatively long residence time for the ignition kernel going through the route to the recirculation zone could be adverse to the survival of ignition kernel, as this allows a greater amount of energy to be lost from the kernel to the surrounding fuel droplets, thus leading to the "extinction" failure mode. In Case (d), the highspeed primary jet near the igniter position was expected to be the primary cause of the downstream movement of ignition kernel. The entrainment effect caused by the primary jet exerted a significant influence on the trajectory of ignition kernel, leading to the "downstream movement" failure mode. As the "breakup" failure mode is a highly transient event, it is difficult to explain utilizing time-averaged flow field and fuel distribution information. As such, time-resolved flow field and fuel distribution measurements are proposed to be conducted in further studies so as to study this failure mode.

\section{CONCLUSIONS}

In the present work, a RQL model combustor ignition test rig was designed and used to determine different ignition failure modes and non-reactive CFD simulations were performed to investigate the relationship between ignition failure modes and flow field/fuel distribution.

Atmospheric ignition, high altitude ignition, and lean blowout experiments were performed to evaluate the ignition and LBO performance of this model combustor. A logarithmic curve was statistically fitted to the liner reference velocity and FAR data, confirming the relationship between flow and fuel influence on spark ignition behaviour. High-speed imaging of ignition events was utilizing to delineate the typical successful ignition process and three ignition failure modes ("extinction", "breakup", and "downstream movement"), along with the ignition kernel path and light intensity time history for each case.

In a typical successful ignition event, a flame kernel formed near the igniter, then moved along the vertical direction into the central recirculation zone and propagated upstream. Subsequently, the flame area expanded and a burner-scale stable flame was established. The ignition failure mode of "extinction" was characterized by the flame kernel quenching in the process of moving into the central recirculation zone. The "breakup" failure mode was characterized by the ignition kernel breaking up, causing the remaining kernel within the central recirculation zone to lack the energy to sustain flame propagation. Lastly, the failure mode of "downstream movement" was characterized by the kernel moving into the downstream area of the combustor where little fuel existed.

CFD simulations of flow field and fuel distribution were conducted at specific conditions representative for the three ignition failure modes. It was found that the "extinction" failure mode was related to relatively low flow velocity and long residence time of the ignition kernel going through the route towards the recirculation zone and the "downstream movement" failure mode was caused by the entrainment effect of the high-speed jet through the primary hole on liner. The 
"breakup" failure mode, a highly transient event, was not explained here, but could be investigated utilizing the timeresolved flow field and fuel distribution measurements proposed to be conducted in further studies.

\section{REFERENCES}

Huang Y., and Yang V. (2009). Dynamics and stability of lean-premixed swirl-stabilized combustion. Progress in energy and combustion science, 35(4), 293-364. doi: 10.1016/j.pecs.2009.01.002

Lecourt R., Linassier G., and Lavergne G. (2011). Detailed characterisation of a swirled air/kerosene spray in reactive and non-reactive conditions downstream from an actual turbojet injection system. In ASME 2011 Turbo Expo: Turbine Technical Conference and Exposition (pp. 185-194). American Society of Mechanical Engineers. doi:10.1115/GT2011-45173

Linassier G., Lecourt R., Villedieu P., Lavergne G., and Verdier H. (2011). Experimental database on high altitude turbojet ignition for numerical simulation validation. ILASSEurope. Estoril, Portugal, 178, 180-192.

Linassier G., Viguier C., Verdier H., Lecourt R., Heid G., and Lavergne G. (2012). Experimental investigations of the ignition performances on a multi-sector combustor under high altitude conditions. In 50th AIAA Aerospace Sciences Meeting including the New Horizons Forum and Aerospace Exposition (p. 934). doi: 10.2514/6.2012-934

Mastorakos E. (2017). Forced ignition of turbulent spray flames. Proceedings of the Combustion Institute, 36(2), 23672383. doi:10.1016/j.proci.2016.08.044

Mckinney R. G., Sepulveda D., Sowa W., and Cheung A. K. (2007). The Pratt \& Whitney TALON X low emissions combustor: Revolutionary results with evolutionary technology. In 45th AIAA Aerospace Sciences Meeting and Exhibit (pp. 2007-386). American Institute of Aeronautics and Astronautics. doi: 10.2514/6.2007-386

Mi X., Zhang C., Wang B., and Lin Y. (2017). Influence of Main Stage Air Splits on the Ignition Performance of TeLESS-II Combustor. In ASME Turbo Expo 2017: Turbomachinery Technical Conference and Exposition (pp. V04AT04A013-V04AT04A013). American Society of Mechanical Engineers.

Mongia H. (2008). Recent progress in comprehensive modeling of gas turbine combustion. In 46th AIAA Aerospace Sciences Meeting and Exhibit (p. 1445). doi: 10.2514/6.20081445

Mongia H. (2011a). Engineering aspects of complex gas turbine combustion mixers part IV: Swirl cup. In 9th Annual International Energy Conversion Engineering Conference (p. 5526). doi: 10.2514/6.2011-5526

Mongia H. (2011b). Engineering aspects of complex gas turbine combustion mixers part V: 40 OPR. In 9th Annual International Energy Conversion Engineering Conference (p. 5527). doi: 10.2514/6.2011-5527

Mosbach T., Sadanandan R., Meier W., and Eggels R. L. G. M. (2010). Experimental analysis of altitude relight under realistic conditions using laser and high-speed video techniques. In ASME Turbo Expo 2010: Power for Land, Sea, and Air (pp. 523-532). American Society of Mechanical Engineers. doi:10.1115/GT2010-22625

Read R. W., Rogerson J. W., and Hochgreb S. (2010). Flame imaging of gas-turbine relight. AIAA journal, 48(9), 1916-1927. doi: 10.2514/1.J050105

Rosa N. G., Linassier G., Lecourt R., Villedieu P., and Lavergne G. (2011). Experimental and numerical study of high-altitude ignition of a turbojet combustor. Heat Transfer Engineering, 32(11-12), 949-956. doi: 10.1080/01457632.2011.556377

Wang B., Zhang C., Lin Y., Hui X., and Li J. (2016). Influence of main swirler vane angle on the ignition performance of TeLESS-II combustor. Journal of Engineering for Gas Turbines and Power, 139(1), 011501. doi: $10.1115 / 1.4034154$

Willis J. D. and Moran A. D. (2000). Industrial RB211 DLE gas turbine combustion update. In ASME 2000 Power for Land, Sea, and Air (pp. V002T02A029). American Society of Mechanical Engineers. doi: 10.1115/2000-GT-0109

$\begin{array}{ll}\text { NOMENCLATURE } \\ \text { RQL } & \text { rich burn-quick mix-lean burn } \\ \mathrm{PZ} & \text { combustor primary zone } \\ \mathrm{DZ} & \text { combustor dilution zone } \\ \mathrm{CTS} & \text { counter-rotating swirler } \\ \mathrm{CFD} & \text { computational fluid dynamics } \\ \mathrm{LBO} & \text { lean blowout } \\ \mathrm{FAR} & \text { fuel-air mass ratio } \\ \mathrm{P}_{3} & \text { liner inlet air total pressure } \\ \Delta \mathrm{P}_{3-4} / \mathrm{P}_{3} & \text { pressure loss across the liner } \\ \mathrm{DPM} & \text { discrete phase model } \\ \mathrm{Wa} \mathrm{a}_{31} & \text { inlet air mass flow rate } \\ \mathrm{Vr} & \text { liner reference velocity } \\ \mathrm{P}_{\mathrm{t}} & \text { total pressure }\end{array}$

\section{ACKNOWLEDGMENTS}

The work at Beihang University was supported by Project 91641109 of the National Natural Science Foundation of China.

\section{APPENDIX A - COPYRIGHT/OPEN ACCESS}

The GPPS policy is that all articles will be Open Source accessible. This article will be published using the Creative Commons Attribution CC-BY 4.0, thus allowing the author(s) to retain their copyright. For answers to frequently asked questions about Creative Commons Licences, please see https://creativecommons.org/faq/.

\section{APPENDIX B - GPPS Presenter Policy and Paper Acceptance}

According to GPPS's presenter attendance policy, a paper cannot be published or be indexed and may not be cited as a published paper until at least one author pays the registration fee and attends the conference. The GPPS reserves the right to withdraw from its publications any paper that is not presented by an author of the paper at the appropriate conference. Any paper that is withdrawn may not be cited as a published paper. 